\title{
PERAMALAN RESPON PENDENGAR DI RADIO MELALUI PESAN SINGKAT (SMS) DENGAN MENGGUNAKAN METODE PEMULUSAN EKSPONENSIAL GANDA (Studi Kasus : Radio Cakti Budhi Bhakti (CBB) 105,4 FM)
}

\author{
Usep Rahmat $^{1, a)}$ Popie Dwi Wahyuni ${ }^{2, b)}$ \\ ${ }^{1,2}$ Program Studi Matematika, FMIPA - UNPAM \\ Email: ${ }^{\text {a) }} \underline{\text { dosen00795@ @unpam.ac.id }}{ }^{\text {b) } 2014100027 @ \text { unpam.ac.id }}$
}

\begin{abstract}
ABSTRAK
Tujuan penelitian ini adalah mengetahui berapakah banyak responden pendengar radio melalui pesan singkat (SMS) dengan menggunakan metode Pemulusan Eksponensial Ganda dan mengetahui berapakah nilai galat yang diperoleh dari metode yang digunakan. Metode yang digunakan yaitu metode survei. Hasil penelitian yaitu prediksi jumlah respon pendengar di Radio Cakti Budhi (CBB) 105,4 FM melalui pesan singkat untuk tiga periode ke depan dengan menggunakan metode exponential smoothing dua parameter dari Holt, yaitu pada bulan Desember 2017sebesar 3799,825 pada bulan Januari 2018 sebesar 3721,354 dan pada bulan Februari 2018 sebesar 3642,883 dengan galat 661,134 dan nilai tengah galat 60,103 .

Kata kunci: Eksponensial Ganda, Holt
\end{abstract}

\section{ABSTRACT}

The purpose of this study is to find out how many respondents listen to the radio through short messages (SMS) using the Double Exponential Smoothing method and find out what the error value obtained from the method used. The method used is a survey method. The results of the study are prediction of the listener's response on Radio Cakti Budhi (CBB) 105.4 FM through short messages for the next three periods using the two parameter exponential smoothing method from Holt, namely in December 2017 at 3799,825 in January 2018 amounting to 3721 , 354 and in February 2018 amounted to 3642,883 with error 661,134 and the mean value of error 60,103.

Keywords: Double Exponential, Holt

\section{PENDAHULUAN}

\subsection{Latar Belakang}

Radio merupakan salah satu jenis media massa di masyarakat. Kini, radio digunakan sebagai salah satu media informasi, edukasi dan hiburan dalam masyarakat (Oramahi, 2012:122). Radio menjadi sarana informasi dan edukasi 
bagi masyarakat melalui berbagai berita yang disampaikan. Sebagai sarana hiburan, radio menyajikan program musik, drama, infotainment dan program hiburan lain. Radio memanjakan pendengarnya dengan memberikan variasi program. Siaran radio dapat menjangkau berbagai lapisan masyarakat. Variasi dalam program hiburan memberikan pilihan pada pendengar dan meningkatkan persaingan antara satu radio dengan radio lain.

Radio berupaya meraih pendengar sebanyak mungkin dengan menyajikan berbagai jenis program, salah satunya Radio CBB 105.4 FM. Radio CBB 105.4 FM merupakan salah satu radio swasta di Jakarta yang memiliki banyak pendengar dan menyajikan program-program dangdut dll. Kemunculan Radio CBB 105.4 FM menambah tingginya persaingan di radio lain dengan programprogram yang ada.

Tingkat persaingan stasiun radio di kota-kota besar cukup tinggi dalam hal merebut perhatian audien. Ditambah lagi dengan adanya radio pemerintah seperti RRI disetiap provinsi membuat radio-radio swasta harus bekerja lebih keras untuk merebut perhatian pendengar melalui program-program siarannya. Maka dari itu, seorang pengelola stasiun radio dituntut untuk memperkaya kreativitasnya dalam membuat sebuah program yang nantinya akan menarik perhatian audien. Sebagai organisasi atau perusahaan, media penyiaran menggunakan manajemen dalam menjalankan kegiatannya, dan setiap orang yang mempunyai tanggung jawab atas bawahan dan sumber daya organisasi lainnya dengan menjalankan fungsi manajemen (Handoko, 1994:17).

Didalam sebuah manajemen perusahaan radio, seorang programmer mempunyai peran penting dalam meningkatnya minat pendengar dan dituntut mempunyai wawasan yang luas tentang perkembangan media elektronik saat ini, program seperti apa yang dibutuhkan oleh pendengar, jenis musik seperti apa yang sedang populer (booming) dan tentunya tidak lari dari standar yang sudah di tetapkan oleh stasiun tersebut. Maka dari itu, para pengelola stasiun radio harus dapat menjalankan fungsi manajemen dengan baik dan sempurna, agar tercapai tujuan yang diinginkan.

Radio CBB 105.4 FM sebagai radio swasta mengalami perkembangan dan kemajuan dari sebelumnya, hal ini bisa dilihat dari sarana-prasarana program dan kru penyiar itu sendiri. Keberadaan Radio CBB 105.4 FM mempunyai peran yang cukup besar bagi khalayak dalam menghibur dan memberikan informasi yang bermanfaat khususnya. Program unggulan dari radio ini salah satunya adalah program Bibir Jakarta dan Gentar. Program Bibir Jakarata dinilai berbeda karena merupakan program musik yang khusus menyajikan lagu-lagu Indonesia terbaik 
dengan diselingi informasi menarik tentang segala hal positif dari Indonesia, sehingga menambah kecintaan pendengar terhadap Indonesia, dan sudah berdiri kurang lebih 15 tahun.

Pada program iniaudiens dapat request lagu favoritnya dan berkirim salam dengan teman - temannya melalui pesan singkat SMS atau interaksi media sosial.

Dari pra penelitian yang penulis lakukan, kepala manajer program Hendy mengatakan siaran Bibir Jakarta memiliki jumlah pendengar lebih banyak dibandingkan dengan program lainnya. Hal ini tampak dari interaksi yang masuk ke layanan sms, dan jejaring sosial. Program Bibir Jakarta sangat digemari oleh Neng manis dan abang sayang (sebutan untuk pendengar CBB) karena memberikan informasi dan musik Dangdut" (Wawancara: Hendy, 17 November 2017).

Berdasarkan latar belakang yang penulis lakukan di Radio Cakti Budhi Bakti (CBB) maka penulis tertarik untuk meneliti tentang " Peramalan Responden Pendengar Diradio Melalui Pesan Singkat (Sms) Dengan Menggunakan Metode Pemulusan Eksponensial Ganda"

\subsection{Rumusan Masalah}

Rumusan masalah pada penelitian ini adalah :

a) Berapa banyak respon pendengar di Radio Cakti Budi Bakti (CBB) 105,4 FM dari data melalui pesan singkat (SMS) dengan menggunakan metode Double Exponential Smoothing (bulan Januari, Februari, Maret, April, Mei, Juni, Agustus,September, Oktober, November, Desember 2017 Januari dan Februari 2018)?

b) Berapakah nilai galat yang diperoleh dari metode tersebut?

\subsection{Tujuan Penelitian}

Tujuan penelitian ini adalah

a) Mengetahui berapakah banyak responden pendengar radio melalui pesan singkat (SMS) dengan menggunakan metode Pemulusan Eksponensial Ganda.

b) Mengetahui berapakah nilai galat yang diperoleh dari metode yang digunakan.

\section{METODOLOGI PENELTIAN}

\subsection{Waktu}


Penelitian dilaksanakan mulai tanggal 4 November 2017 sampai dengan 4 Desember 2017

\subsection{Tempat Penelitian}

Penelitian dilaksanakan di Radio Cakti Budhi Bakhti (CBB) 105,4 FM

\subsection{Metode Pengumpulan Data}

Data yang digunakan dalam membuat laporan ini adalah data yang diperoleh dari Radio Cakti Budhi Bakhti (CBB) 105,4 FM. Pengumpulan data dilakukan untuk memperoleh informasi yang dibutuhkan dalam rangka mencapai tujuan penelitian. Tujuan yang diungkapkan dalam bentuk hipotesis merupakan jawaban sementara terhadap petanyaan penelitian. Jawaban itu masih perlu diuji secara empiris, dan untuk maksud inilah dibutuhkan pengumpulan data. Data yang dikumpulkan ditentukan oleh variabel-variabel yang ada dalam hipotesis. Data itu dikumpulkan oleh sampel yang telah ditentukan sebelumnya. Sampel tersebut terdiri atas sekumpulan unit analisis sebagai sasaran penelitian.

\subsection{Metode Analisis Data}

Dalam analisis data penelitian ini, penelitian menggunakan eksponensial ganda (Double Exponentian Smoothing). Adapun tahapan-tahapannya adalah sebagai berikut :

a. Menentukan smoothing pertama $\left(S^{\prime}{ }_{t}\right)$

$$
S_{t}^{\prime}=\alpha X_{t}+(1-\alpha) S_{t-1}^{\prime}
$$

b. Menentukan smoothing ke dua $\left(S^{\prime \prime}{ }_{t}\right)$

$$
{S^{\prime \prime}}_{t}=\alpha{S^{\prime}}_{t^{+}}+(1-\alpha){S^{\prime \prime}}_{t-1}
$$

c. Menentukan besarnya konstanta $\left(a_{t}\right)$

$$
\begin{aligned}
a_{t} & =S^{\prime}{ }_{t}+\left({S^{\prime}}_{t}+{S^{\prime \prime}}_{t}\right) \\
& =2{S^{\prime}}^{\prime}{ }_{t}+{S^{\prime \prime}}{ }_{t}
\end{aligned}
$$

d. Menentukan besarnya Trend (bt)

$$
\mathrm{b}_{\mathrm{t}}=\beta\left(S_{t}-S_{t-1}\right)+(1-\mathrm{y}) b_{t-1}
$$

e. Menentukan besarnya peramalan $\left(F_{t+m}\right)$

$$
F_{t+m}=S_{t}+b_{t} \mathrm{~m}
$$

Keterangan :

$S^{\prime}{ }_{t} \quad$ : Nilai exponential smoothing tunggal

$S^{\prime \prime}{ }_{t} \quad$ : Nilai exponential smoothing ganda

$\mathrm{b}_{\mathrm{t}} \quad$ : Trend pada periode ke $\mathrm{t}$ 
$\alpha \quad:$ Untuk pemulusan nilai observasi

$\beta \quad$ : Parameter kedua untuk pemulusan trend

$F_{t+m} \quad$ : Hasil peramalan ke-m

$m \quad$ : Jumlah periode ke depan yang akan di ramalkan

\section{HASIL DAN PEMBAHASAN}

\subsection{Hasil Data Penelitian}

Dengan menggunakan langkah-langkah yang telah diuraikan pada bab sebelumnya, maka akan dibahas Forecasting (Peramalan) jumlah penginputan transaksi setor tabungan menggunakan metode double smoothing secara manual.

Berikut data pesan singkat di Radio CBB :

Tabel 3.1 Hasil Data Penelitian

\begin{tabular}{|c|c|c|}
\hline Periode & Bulan & Data Pesan Singkat $\left(X_{t}\right)$ \\
\hline 1 & Januari 2017 & 3469 \\
\hline 2 & Februari 2017 & 4513 \\
\hline 3 & Maret 2017 & 4500 \\
\hline 4 & April 2016 & 4333 \\
\hline 5 & Mei 2016 & 6689 \\
\hline 6 & Juni 2016 & 3823 \\
\hline 7 & Juli 2016 & 969 \\
\hline 8 & Agustus 2016 & 3137 \\
\hline 9 & September 2016 & 3672 \\
\hline 10 & Oktober 2016 & 4994 \\
\hline 11 & November 2016 & 4412 \\
\hline
\end{tabular}

Penyelesaian dengan menggunakan rumus Double Exponensial Smoothing secara manual:

$S^{\prime}{ }_{t} \quad$ : Nilai exponential smoothing tunggal

$S^{\prime \prime}{ }_{t} \quad$ : Nilai exponential smoothing ganda

$\mathrm{b}_{\mathrm{t}} \quad$ : Trend pada periode ke $\mathrm{t}$

$\alpha \quad$ : Untuk pemulusan nilai nhservasi 
$\beta \quad$ : Parameter kedua untuk pemulusan trend

$F_{t+m}$ : Hasil peramalan ke-m

$m$ : Jumlah periode ke depan yang akan di ramalkan

1 : Untuk pemulusan nilai observasi

\subsection{Hasil Perhitungan}

Berikut ini adalah tabel perhitungan data yang diperoleh dengan menggunakan metode Double Exponential Smoothing untuk tiga periode kedepan:

Tabel 3.2 Hasil Perhitungan Peramalan

\begin{tabular}{|c|c|c|c|c|c|}
\hline Periode & Bulan & $\begin{array}{c}\text { Input } \\
\text { Transaksi }\left(X_{t}\right)\end{array}$ & $\begin{array}{l}\text { Nilai Ramalan } \\
\left(S_{t}\right)\end{array}$ & $\begin{array}{c}\text { Trend } \\
\left(b_{t}\right)\end{array}$ & $\begin{array}{c}\text { Hasil } \\
\text { Ramalan } \\
\text { (Ft) }\end{array}$ \\
\hline 1 & Jan-17 & 4369 & 4369 & 144 & \\
\hline 2 & Feb-17 & 4513 & 4513 & 144 & 4513 \\
\hline 3 & Mar-17 & 4500 & 4625,6 & 134,58 & 4657 \\
\hline 4 & Apr-17 & 4333 & 4674,744 & 108,949 & 4760,18 \\
\hline 5 & Mei-17 & 6689 & 5164,755 & 223,267 & 4783,693 \\
\hline 6 & Jun-17 & 3823 & 5075,018 & 129,366 & 5388,022 \\
\hline 7 & Jul-17 & 969 & 4357,307 & $-124,757$ & 5204,384 \\
\hline 8 & Agu-17 & 3137 & 4013,44 & $-190,49$ & 4232,55 \\
\hline 9 & Sep-17 & 3672 & 3792,76 & $-199,547$ & 3822,951 \\
\hline 10 & Okt-17 & 4944 & 3863,371 & $-118,5$ & 3593,214 \\
\hline 11 & Nov-17 & 4412 & 3878,297 & $-78,471$ & 3744,871 \\
\hline 12 & Des-17 & & & & \\
\hline 13 & Jan-18 & & & & \\
\hline 14 & Feb-18 & & & & \\
\hline
\end{tabular}

Hasil pada tabel diatas di peroleh melalui perhitungan manual sebagai berikut :

$$
\begin{aligned}
& S_{1}=X_{1} \\
& \alpha=0,2 \\
& \beta=0,3 \\
& b_{1}=X_{2}-X_{1}
\end{aligned}
$$

\section{Perhitungan Peramalan}


Dari data yang terlampir di tabel hasil penelitian maka dapat kita hitung pada tiap-tiap periode sebagai berikut:

a. Periode 1

$$
\begin{aligned}
X_{1} & =4369 \\
S_{1} & =X_{1}=4369 \\
b_{1} & =X_{2}-X_{1} \\
& =4513-4369=144 \\
F_{t+m} & =S_{0}+\mathrm{m} \\
F_{t+m} & =0
\end{aligned}
$$

b. Periode 2

$$
\begin{aligned}
X_{2} & =4513 \\
S_{2} & =\alpha X_{2}+(1-\alpha)\left(S_{1}+b_{1}\right) \\
& =0,2(4513)+(1-0,2)(4369+144) \\
& =902,6+0,8(4513) \\
& =902,6+3610,4 \\
& =4513 \\
b_{2} & =\beta\left(S_{2}-S_{1}\right)+(1-\beta) b_{1} \\
& =0,3(4513-4369)+(1-0,3) 144 \\
& =0,3(144)+0,7(144) \\
& =43,2+100,8 \\
& =144 \\
F_{2} & =S_{1}+b_{1} m \\
& =4369+144(1) \\
& =4513
\end{aligned}
$$

c. Periode 3

$$
\begin{aligned}
X_{3} & =4500 \\
S_{3} & =\alpha X_{3}+(1-\alpha)\left(S_{2}+b_{2}\right) \\
& =0,2(4500)+(1-0,2)(4513+144) \\
& =900+0,8(4657) \\
& =4.625,6 \\
b_{3} & =\beta\left(S_{3}-S_{2}\right)+(1-\beta) b_{2} \\
& =0,3(4625,6-4513)+(1-0,3) 144 \\
& =0,3(112,6)+0.7(144) \\
& =33,78+100,8 \\
& =134,58 \\
F_{3} & =S_{2}+b_{2} m \\
& =4513+144(1) \\
& =4657
\end{aligned}
$$

Dan seterusnya sampai dengan ke-11 


\section{Perhitungan Galat (Error)}

Galat (error) biasa disimbolkan dengan $e_{1}$ dan berikut perhitungan galat untuk peramalan diatas :

a. Galat (Error)

$$
\begin{aligned}
& e_{i}=X_{i}-F_{i} \\
& e_{1}=X_{1}-F_{1}=4369-0=4369 \\
& e_{2}=X_{2}-F_{2}=4513-4513=0 \\
& e_{3}=X_{3}-F_{3}=4500-4657=-157
\end{aligned}
$$

dan seterusnya sampai dengan ke-11, maka diperoleh

$$
\begin{aligned}
\sum_{i=1}^{15} e_{i}= & 4369+0+(-157)+(-427,18)+1905,307+(-1565,02)+(-4235,38) \\
& +(-1095,55)+(-150,951)+1350,786+667,128=661,1347
\end{aligned}
$$

b. Nilai Tengah Galat (Mean Error)

$$
M E=\frac{\sum_{i=1}^{n} e_{i}}{n}=\frac{661,1347}{11}=60,103
$$

\subsection{Pembahasan}

\section{1) Peramalan}

Dalam perhitungan ramalan pada tiga periode mendatang tepatnya F12, F13, F14 banyak jumlah respon pendengar radio Cakti Budhi Bakhti (CBB) 105,4 FM terhadap pesan singkat dengan menggunakan metode Double Exponential Smoothing bulan Desember 2017, Januari, dan Februari 2018 adalah :

\section{Periode 12}

$$
\begin{aligned}
F_{12} & =S_{11}+b_{11} m \\
& =3878,297-78,471(1) \\
& =3799,825
\end{aligned}
$$

Periode 13

$$
\begin{aligned}
F_{13} & =S_{11}+b_{11} m \\
& =3878,297-78,471(2) \\
& =3721,354
\end{aligned}
$$

Periode 14

$$
\begin{aligned}
F_{14} & =S_{11}+b_{11} m \\
& =3878,297-78,471(3) \\
& =3642,883
\end{aligned}
$$

Berikut tabel hasil perhitungan ramalan untuk tiga periode kedepan: 


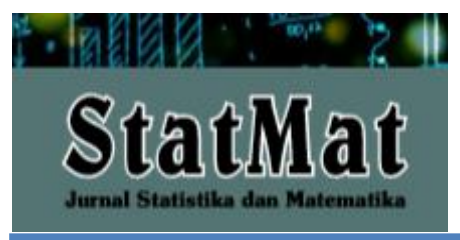

Tabel 2.3 Hasil Perhitungan Peramalan Tiga Periode Selanjutnya

\begin{tabular}{|c|c|c|c|c|c|}
\hline Periode & Bulan & $\begin{array}{c}\text { Data Pesan } \\
\text { Singkat }\left(\boldsymbol{X}_{\boldsymbol{t}}\right)\end{array}$ & $\begin{array}{c}\text { Nilai Ramalan } \\
\left(\boldsymbol{S}_{\boldsymbol{t}}\right)\end{array}$ & $\begin{array}{c}\text { Trend } \\
\left(\boldsymbol{b}_{\boldsymbol{t}}\right)\end{array}$ & $\begin{array}{c}\text { Hasil } \\
\text { Ramalan } \\
(\mathbf{F t})\end{array}$ \\
\hline 1 & Jan-17 & 4369 & 4369 & 144 & \\
\hline 2 & Feb-17 & 4513 & 4513 & 144 & 4513 \\
\hline 3 & Mar-17 & 4500 & 4625,6 & 134,58 & 4657 \\
\hline 4 & Apr-17 & 4333 & 4674,744 & 108,949 & 4760,18 \\
\hline 5 & Mei-17 & 6689 & 5164,755 & 223,267 & 4783,693 \\
\hline 6 & Jun-17 & 3823 & 5075,018 & 129,366 & 5388,022 \\
\hline 7 & Jul-17 & 969 & 4357,307 & $-124,757$ & 5204,384 \\
\hline 8 & Agu-17 & 3137 & 4013,44 & $-190,49$ & 4232,55 \\
\hline 9 & Sep-17 & 3672 & 3792,76 & $-199,547$ & 3822,951 \\
\hline 10 & Okt-17 & 4944 & 3863,371 & $-118,5$ & 3593,214 \\
\hline 11 & Nov-17 & 4412 & 3878,297 & $-78,471$ & 3744,871 \\
\hline 12 & Des-17 & & & & 3799,825 \\
\hline 13 & Jan-18 & & & & 3721,354 \\
\hline 14 & Feb-18 & & & & 3642,883 \\
\hline
\end{tabular}

Setelah, dilakukan proses perhitungan dengan menggunakan metode pemulusan Holt, dapat diketahui hasil ramalan tiap-tiap periodenya, bahwa hasil ramalan khusunya tiga periode kedepan yaitu pada periode ke-12 sebesar 3799,825 periode ke-13 sebesar 3721,354 dan periode ke-14 sebesar 3642,883

\section{2) Galat}

Dalam perhitungan galat pada tiga periode terakhir tepatnya F9, F10, F11 galat peramalan atas respon pendengar di radio Cakti Budhi Bakti (CBB) 105,4 FM terhadap pesan singkat pada bulan Januari, Februari, dan Maret 2017 adalah :

$$
\begin{aligned}
& e_{9}=X_{9}-F_{9}=3672-3822,951=-150,951 \\
& e_{10}=X_{10}-F_{10}=4944-3593,214=1350,786 \\
& e_{11}=X_{11}-F_{11}=4412-3744,871=667,128
\end{aligned}
$$


Metode peramalan respon pendengar Radio Cakti Budhi Bakhti (CBB)105,4 FM terhadap pesan singkat dengan menggunakan metode Double Exponential Smoothing tepat digunakan dengan analisis galat dengan galat 661,134 dan nilai tengah galat 60,103 .

\section{KESIMPULAN DAN SARAN \\ 4.1 Kesimpulan}

Dari hasil perhitungan dan analisis yang dilakukan maka peneliti dapat menyimpulkan :

1. Bahwa jumlah respon pendengar di Radio Cakti Budhi (CBB) 105,4 FM melalui pesan singkat untuk tiga periode ke depan dengan menggunakan metode exponential smoothing dua parameter dari Holt, yaitu pada bulan Desember 2017sebesar 3799,825 pada bulan Januari 2018 sebesar 3721,354 dan pada bulan Februari 2018 sebesar 3642,883.

2. Metode peramalan respon pendengar di Radio Cakti Budhi Bakhti (CBB) 105,4 FM dengan menggunakan metode Double Exponential Smoothing tepat digunakan dengan analisis galat dengan galat 661,134 dan nilai tengah galat 60,103 .

\subsection{Saran}

Keberadaan pendengar sangat penting bagi sebuah radio, banyak atau tidaknya pendengar suatu radio dapat ditentukan dari jumlah pendengar setiap acara diradio tersebut. Hasil penelitian dan peramalan diatas kemungkinan besar bisa sama hasilnya dengan kenyataan di masa yang akan datang, tetapi bisa juga tidak, dan untuk lebih meningkatkan jumlah respon pendengar di setiap acara dibutuhkan media promosi selain media teresterial sepert siaran dengan menggunakan media streaming, pembuatan spot iklan masing masing acara untuk disiarkan secara periodic,dan yang pasti adalah promosi yang kuat dengan brand image sesuai dengan slogan radio tersebut (Bandar Dangdut Jakarta).

\section{DAFTAR PUSTAKA}

Arikunto, Suharsimi. 2002. "Prosedur Penelitian : Suatu Pendekatan Praktek", Edisi Revisi V, Jakarta: PT Rineka Cipta.

Arsyad, Lincolin. 1993. Peramalan Bisnis. Yogyakarta : BPFE

Assauri, Sofjan. 1984. Teknik dan Metode Peramalan. Depok : Lembaga Penerbit FE-UI. 
Dwi Anggoro, Yugo. 2011. Perbandingan Metode Exponential Smoothing dengan Pemulusan Untuk Memprediksi Jumlah Pelapor SPT Masa PPH Pasal 21. Bandung : Tugas Akhir.

Makridakis, Spyros. 1987. Analisis Runtun Waktu. Jakarta : Karunika.

SC, Wheelwright; Makridakis, Spyros, Victor E, McGee. 1999. Metode dan Aplikasi Peramalan. Jakarta : Binarupa Aksara. 